\title{
Association of a Duodenal Follicular Lymphoma and Hereditary Nonpolyposis Colorectal Cancer
}

Christophe Rosty, M.D., Josette Brière, M.D., Christophe Cellier, M.D., Eric Delabesse, M.D., Françoise Carnot, M.D., Jean-Philippe Barbier, M.D., Pierre Laurent-Puig, M.D., Ph.D.

Services d'Anatomie Pathologique (CR, JB, FC), Hépatogastro-entérologie (CC, J-PB), Chirurgie Digestive et Générale (PLP), Hôpital Laennec; Laboratoire d'Hématologie, Hôpital Necker (ED); and Unité INSERM

U490 (CR, PLP), Paris, France

Hereditary nonpolyposis colorectal cancer (HNPCC) is an inherited predisposition to colorectal and endometrial cancers caused by germline mutation of mismatch repair genes, with $h M L H 1$ and hMSH2 underlying the majority of the cases. Although lymphoid tumors are the most common tumors in mouse models for HNPCC, lymphomas are almost never encountered in patients who have HNPCC, except in rare families with germline homozygous deletion of $h M L H 1$. We report the case of a 53-year-old man who had a history of colon cancers related to constitutional $h M L H 1$ mutation and who was diagnosed as having a duodenal follicular lymphoma. This diagnosis was supported by $\mathbf{I g H}$ $B C L 2$ rearrangement and BCL2 immunoreactivity in tumor cells. The association of both of these possibly related rare diseases has never been reported. To clarify this relationship, we searched for hMLH1 expression and mismatch repair deficiency in the duodenal lymphoma. hMLH1 immunostaining was positive in lymphoid tumor cells, and no microsatellite instability was detected. In agreement with mouse models for HNPCC, these results suggest the involvement of alternative mechanisms to complete mismatch repair deficiency for lymphomagenesis in HNPCC syndrome.

KEY WORDS: Follicular lymphoma, Hereditary nonpolyposis colorectal cancer, Immunohistochemistry, Microsatellite instability.

Mod Pathol 2000;13(5):586-590

Copyright (C) 2000 by The United States and Canadian Academy of Pathology, Inc.

VOL. 13, NO. 5, P. 586, 2000 Printed in the U.S.A.

Date of acceptance: November 22, 1999.

Address reprint requests to: Christophe Rosty, Laboratoire d'Anatomie Pathologique, Hôpital Laennec, 42 rue de Sèvres, 75340 Paris Cedex 07,

France; e-mail: christopherosty@hotmail.com; fax: 33144396936.
Hereditary nonpolyposis colorectal cancer (HNPCC) is one of the most common cancer predisposition syndromes, inherited in an autosomal dominant fashion and characterized by early-onset colon carcinomas. Germline mutations in $h M L H 1$ and $h M S H 2$ account for most of the kindreds, whereas mutations in hPMS1, hPMS2, and hMSH6 are rare (1). Proteins synthesized by these genes are involved in the recognition and repair of DNA mismatches. In tumors, the wild-type allele is lost and instability of the length of microsatellites occurs, referred to as the replicative error (RER)-positive or microsatellite instability (MSI)-positive phenotype.

The gastrointestinal (GI) tract is the most common extranodal site for the occurrence of nonHodgkin's lymphomas. Approximately half of them are B-cell lymphomas, including most commonly mucosa-associated lymphoid tissue lymphoma, lymphomatous polyposis (mantle cell lymphoma), and Burkitt/Burkitt-like lymphoma (2). Follicular lymphomas are rare in this region, constituting from 1 to $3 \%$ of GI tract lymphomas (3).

We report the case of a 53-year-old man with a duodenal follicular lymphoma occurring 18 years after a colon cancer related to HNPCC, with germline $h M L H 1$ mutation. Although lymphomas are the most common tumors in mouse models for HNPCC, the association has never been reported in humans. To determine the putative role of the mismatch repair system in this tumor, we assessed the MSI phenotype by the use of five microsatellites and immunohistochemistry with antibodies against hMLH1 and hMSH2.

\section{CASE REPORT}

A 53-year-old asymptomatic man was referred for periodic GI tract examination in the follow-up of a history of two colon cancers. At the age of 35, the patient was operated on with left colectomy for an adenocarcinoma of the ascending colon (classified T2N0M0). Sixteen years later, an in situ adenocar- 
cinoma of the right colon was found and a total colectomy with ileorectal anastomosis was performed. The family of the patient met the Amsterdam criteria for HNPCC: one first-degree relative, his mother, and two successive generations also had a history of colorectal cancer. A screening procedure for the identification of $h M L H 1$ mutation has found an in-frame deletion of the codon 616 .

In October 1998, upper GI endoscopy showed proximal duodenal mucosa peppered with multiple white fleshy polyps of 0.2 to $0.5 \mathrm{~cm}$. There was no evidence of recurrence of GI tract carcinoma. Multiple biopsies were performed.

\section{MATERIALS AND METHODS}

Duodenal and ileal biopsies were fixed in $10 \%$ formalin:acetic acid (20:1) for histologic and immunohistochemical studies or were immediately frozen in liquid nitrogen and stored at $-80^{\circ} \mathrm{C}$ for DNA analysis. Tissue sections were stained with hematoxylin, eosin, and saffron. Immunostaining was performed on paraffin sections with an automated immunohistochemical processor (Ventana, Strasbourg, France) using a panel of antibodies against the following antigens: CD20, CD3, and BCL2 (Dako, Trappes, France); CD5, CD10, and BCL1 (Novocastra, Le Perray en Yvelines, France); and hMLH1 and hMSH2 (Calbiochem, Meudon, France).

DNA was extracted from frozen tissue (two duodenal samples and one ileal sample) and peripheral blood lymphocytes by proteinase $\mathrm{K}$ digestion and phenol-chloroform purification. A panel consisted of three dinucleotide repeats (D2S123, D5S346, D17S250), and two poly(A) repeats (BAT-25 and BAT-26) were used for the analysis of microsatellite instability according to the International Workshop on Microsatellite Instability (4). Polymerase chain reaction (PCR) assays were performed in $20 \mu \mathrm{L} 50$ $\mathrm{mm} \mathrm{KCl,} 10 \mathrm{~mm}$ Tris (pH 8.3), $1.5 \mathrm{~mm} \mathrm{MgCl}_{2}, 0.2 \mathrm{~mm}$ each dNTP, 20 pmol each primer, 50 ng DNA, and 0.1 unit of Taq polymerase (Perkin-Elmer, Courtaboeuf, France). The forward primer of each primer pair was end-labeled with a fluorochrome. After a denaturing step at $94^{\circ} \mathrm{C}$ for $5 \mathrm{~min}$, amplification was performed for 35 cycles consisting of $94^{\circ} \mathrm{C}$ for 30 seconds, $50^{\circ} \mathrm{C}$ for 30 seconds, and $72^{\circ} \mathrm{C}$ for 1 min. PCR products were loaded on an ABI 310 sequencer (Applied-Biosystems, Courtaboeuf, France) for fragment analysis.

BCL2 gene rearrangement with $I g H$ locus was analyzed by PCR amplification on $100 \mathrm{ng}$ of DNA, $50 \mathrm{~mm} \mathrm{KCl}, 2 \mathrm{~mm} \mathrm{MgCl}_{2}, 0.2 \mathrm{~mm}$ dNTP, $0.25 \mu \mathrm{M}$ oligonucleotide primers specific for the major breakpoint region of the $B C L 2$ gene $\left(5^{\prime}\right.$-TAT GGT GGT TTG ACC TTT AG-3') and the JH segments of the IgH gene ( 5 ' -ACC TGA GGA GAC GGT GAC CAG
GGT-3'), and $2 \mathrm{U}$ Taq polymerase in a total volume of $50 \mu \mathrm{L}$. Amplification was performed for 35 cycles with a first denaturation step for $3 \mathrm{~min}$ at $92^{\circ} \mathrm{C}, 35$ cycles at $92^{\circ} \mathrm{C}$ for 30 seconds, hybridization at $56^{\circ} \mathrm{C}$ for $1 \mathrm{~min}$, and polymerization at $72^{\circ} \mathrm{C}$ for $1 \mathrm{~min}$, increased to $10 \mathrm{~min}$ in the last cycle. PCR products were analyzed on a polyacrylamide gel. B-cell clonality was assessed using the analysis of $\operatorname{IgH}$ rearrangements with FR1c and FR2-56 systems as previously described (5). IgH PCR products were separated on an ABI 310 sequencer.

\section{RESULTS}

\section{Light Microscopic and Immunohistochemical Examination}

Multiple biopsies of the duodenum showed villi expanded by a nodular lymphoid proliferation with erosions of the superficial epithelium (Fig. 1). This infiltrate was composed of monomorphous small lymphoid cells with irregular nuclei, indistinct nucleoli, and scant cytoplasm. There was some exocytosis of lymphoid cells in the superficial epithelium but no lymphoepithelial lesions in the glands. These findings were consistent with the diagnosis of follicular lymphoma. Results of ileal biopsies were normal.

Immunohistochemical staining with CD20, CD10, and BCL2 was uniformly positive in the lymphoid cells of the nodular proliferation. CD5 staining was negative as was BCL1. Rare T lymphocytes, positive for CD3, were present throughout the lesion. Tumor lymphoid cells exhibit nuclear immunostaining for hMLH1 and hMSH2 (Fig. 2).

To complete the workup of this lymphoma, biopsies of the jejunum and the rectum were performed, as well as a bone marrow biopsy, a head and neck examination, and a thoraco-abdominal computed tomography. There was no evidence of extraduodenal localization of the lymphoma.

\section{Molecular Genetic Analysis}

Translocation $\mathrm{t}(14 ; 18)(\mathrm{q} 32 ; \mathrm{q} 21)$ is a hallmark of follicular lymphoma. The translocation fused $\operatorname{IgH}$ locus to BCL2 locus. The breakpoints are usually sparse in a $30-\mathrm{kbp}$ region, but in nearly $70 \%$ of $t(14 ; 18)$, the breakpoint occurs in the $3^{\prime}$ noncoding region of $B C L 2$ gene therefore named major breakpoint region (6). An IgH-BCL2 rearrangement at the major breakpoint region was detected by PCR in the DNA sample obtained from duodenal biopsies but not from the ileal sample (Fig. 3). No IgH monoclonal rearrangement of the immunoglobulin heavy chain gene was detected in the duodenum or the ileum (data not shown). 



FIGURE 1. Polypoid appearance of the duodenal lesion showing a nodular growth pattern of the mucosae $(\mathbf{A})$, with a predominance of atypical small cleaved cells with irregular and angular nuclei and scattered large noncleaved cells (B, C).

From the same DNA sample, PCR amplification with the five primer pairs D2S123, D5S346, D17S250, BAT-25, and BAT-26 did not demonstrate extra bands from tumor samples when compared with amplification from normal DNA (data not shown).

\section{DISCUSSION}

We report the first case of a duodenal follicular lymphoma occurring in a patient who had HNPCC with a hemizygous mutation of $h M L H 1$. The duodenal lymphoid proliferation had a nodular architecture with small cleaved lymphocytes that exhibited IgH-BCL2 rearrangement by PCR and BCL2 oncoprotein enhanced expression by immunohistochemistry. These features are consistent with the diagnosis of follicular B-cell lymphoma. The absence of monoclonal rearrangement of the immunoglobulin heavy chain gene detected by PCR does not exclude a clonal B-cell proliferation as follicular lymphoma has a low detection rate of $75 \%$ using consensus IgH PCR systems because of a somatic mutation activity (5). Mucosa-associated lymphoid tissue lymphomas, the most common GI tract lymphomas, can be ruled out because of the morphology, the absence of lymphoepithelial lesions, positivity for CD10, and BCL2 rearrangement. Although the endoscopic presentation may suggest multiple lymphomatous polyposis, the immunohistochemical profile and the molecular rearrangement rule out mantle cell lymphoma, characterized by CD5positive cells, CD10-negative cells, and cyclin D1enhanced expression related to $(11 ; 14)$ translocation.

Follicular lymphomas are rare in the GI tract. The most common site is the small intestine, especially the terminal ileum. The lesion may present with obstruction or multiple mucosal polyps. Like their lymph node-based counterparts, follicular GI lymphomas carry the $(14 ; 18)(\mathrm{q} 32 ; \mathrm{q} 21)$ translocation, resulting in the juxtaposition of the BCL2 gene with the immunoglobulin heavy chain locus on chromosome 14. Consequently, BCL2 expression is enhanced and detectable by immunohistochemical staining in $75 \%$ of the cases (3).

The interest of this case report is the possible relationship between a rare GI tract lymphoma and HNPCC, although a random association cannot be ruled out. This cancer predisposition syndrome accounts for $5 \%$ of all colorectal carcinomas. Constitutional mutations of mismatch repair (MMR) genes $h M L H 1$ and $h M S H 2$ underlie $60 \%$ and $38 \%$ of HNPCC, respectively (7). In tumors, the inactivation of both alleles leads to the characteristic MSIpositive phenotype and altered expression of the involved protein. Thus, immunohistochemistry with antibodies against hMLH1 and hMSH2 on paraffin-embedded tissue seems to be a rapid and efficient method for prescreening tumors for mutations in the MMR genes (8).

Besides HNPCC, MSI has also been reported in a variety of sporadic tumors with a mutator phenotype. In hematologic malignancies, MSI is rare and dependent on the type of tumor. No MSI was de- 



FIGURE 2. Immunohistochemical stainings. Left, BCL2 protein is strongly expressed by virtually all of the tumor small cleaved cells. Right, Nuclear immunoreactivity with hMLH1 in epithelial cells and lymphoid tumor cells.



FIGURE 3. IgH-BCL2 rearrangement analysis by polymerase chain reaction. The two duodenal samples showed a DNA rearrangement of IgH-BCL2, but the ileal sample was negative. RL $10 \%$ and $1 \%$ : dilution of an IgH-BCL2 positive RL cell line (from the American Type Culture Collection) in peripheral blood lymphocytes; $1 \mathrm{~kb}$ ladder: molecular weight ladder (Life Technologies).

tected in a study of 69 B-cell non-Hodgkin's lymphomas, except in one AIDS-related lymphoma (9). In a series of 40 follicular lymphomas, 7 (17\%) showed evidence of at least one locus with shifted bands in tumor DNA, but only 2 cases (5\%) displayed instability in more than one microsatellite locus (10). Discrepancies in the method and interpretation of the results emphasize that the recently determined standard criteria should now be used for the determination of the MSI phenotype (4).

In addition to colorectal cancer, the spectrum of tumors in HNPCC includes cancers of the endometrium, stomach, ovary, small intestine, and urinary tract. Sebaceous neoplasms, keratoacanthomas, might be encountered in Muir-Torre syndrome. It is interesting that lymphoma is not an expected tumor, although it is the most common tumor in mouse models for HNPCC. Mice carrying a hemi- zygous or homozygous deficiency in Mlh1, Msh2, Pms1, or Msh6 succumb rapidly to lymphomas, far more frequently than to HNPCC-like tumors (1115). Mlh $1+/-$ and $-/-$ mice develop both T-cell and B-cell lymphomas outside the GI tract, with higher frequency and earlier onset in Mlh1-/mice $(12,13)$. The precise types of lymphoma were not specified in these studies. Lymphomas in Msh2 mutant mice are exclusively of T-cell origin, mostly lymphoblastic $(11,14)$. Lymphomas occur in extra-GI tract localization in the majority of the cases.

In our case, microsatellite analysis did not demonstrate extra bands in PCR products from tumor DNA compared with normal DNA, consistent with an absence of MSI. A positive immunostaining for hMLH1 was detected in the duodenal follicular lymphoma, suggesting that lymphoid tumor cells still have the wild-type allele of $h M L H 1$. If we hypothesize that this lymphoma is related to HNPCC, then these results indicate a different pathway in the lymphomagenesis compared with the pathway of colorectal carcinoma tumorigenesis involving alteration of both MMR gene alleles. In HNPCC mouse models, all tumors were MSI positive in homozygous deficient mice, although almost none of those in hemizygous deficient mice displayed MSI (11). Moreover, early-onset hematologic malignancies have been reported in patients who have HNPCC only in rare offspring who constitutionally lack both wild-type $h M L H 1$ alleles $(16,17)$. Children with homozygous $h M L H 1$ mutation were diagnosed with chronic myeloid leukemia, non-Hodgkin's lymphoma, and acute leukemia by the age of 3 . These findings show that the difference in the spectrum of HNPCC-related tumors between human and mouse is not caused only by speciesdependent tumor susceptibility (18). It suggests that both alleles need to be altered constitutionally 
for the early-onset occurrence of lymphomas in human and mouse. In this situation, lymphomas exhibit MSI. In patients who have classical HNPCC or in hemizygous deficient mice, alteration of the wild-type allele probably may be deleterious in lymphoid cells. MMR-deficient cells have a high rate of frameshift mutations, particularly on genes with repeated sequences, such as mononucleotide tracts. These mutations may generate novel peptides on the cell surface, such as $\beta 2$-microglobulin, that lead to a T-cell-mediated immune response (19). Thus, lymphoid tumor development, resulting from the loss of the wild-type allele, may be efficiently controlled by the immune system. When lymphomas occur as a rare manifestation of HNPCC, they are more likely the consequence of other rare downstream mutation events triggered by the hemizygous mutation in the MMR gene. These mutations may affect oncogenes and tumor suppressor genes that are important for lymphomagenesis but seldom mutated because of the absence of complete inactivation of the MMR system.

In summary, this observation highlights for the first time the possible association of a follicular intestinal lymphoma and HNPCC. The absence of MSI and the positive immunostaining with hMLH1 suggest that tumor lymphoid cells still have a functional MMR system. Although a random association may not be excluded, the localization in the duodenum of the follicular lymphoma raises the hypothesis of a putative role of the exposure to mutagenic exogenous agents, the same that may explain the tissue specificity of HNPCC-related tumors (11) and that also might alter lymphoid cells of the intestinal mucosa.

\section{REFERENCES}

1. Kinzler KW, Vogelstein B. Lessons from hereditary colorectal cancer. Cell 1996;87:159-70.

2. Isaacson PG. Gastrointestinal lymphomas of T- and B-cell types. Mod Pathol 1999;12:151-8.

3. LeBrun DP, Kamel OW, Cleary ML, Dorfman RF, Warnke RA. Follicular lymphomas of the gastrointestinal tract. Pathologic features in 31 cases and bcl-2 oncogenic protein expression. Am J Pathol 1992;140:1327-35.

4. Boland CR, Thibodeau SN, Hamilton SR, Sidransky D, Eshleman JR, Burt RW, et al. A National Cancer Institute Workshop on Microsatellite Instability for cancer detection and familial predisposition: development of international criteria for the determination of microsatellite instability in colorectal cancer. Cancer Res 1998;58:5248-57.

5. Aubin J, Davi F, Nguyen-Salomon F, Leboeuf D, Debert C, Taher M, et al. Description of a novel FR1 IgH PCR strategy and its comparison with three other strategies for the detection of clonality in B cell malignancies. Leukemia 1995;9: 471-9.

6. Korsmeyer SJ. Bcl-2 initiates a new category of oncogenes: regulators of cell death. Blood 1992;80:879-86.

7. Peltomaki P, Vasen HF. Mutations predisposing to hereditary nonpolyposis colorectal cancer: database and results of a collaborative study. The International Collaborative Group on Hereditary Nonpolyposis Colorectal Cancer. Gastroenterology. 1997;113:1146-58.

8. Thibodeau SN, French AJ, Roche PC, Cunningham JM, Tester DJ, Lindor NM, et al. Altered expression of hMSH2 and hMLH1 in tumors with microsatellite instability and genetic alterations in mismatch repair genes. Cancer Res 1996;56:4836-40.

9. Gamberi B, Gaidano G, Parsa N, Carbone A, Roncella S, Knowles DM, et al. Microsatellite instability is rare in B-cell non-Hodgkin's lymphomas. Blood 1997;89:975-9.

10. Randerson J, Cawkwell L, Jack A, Child JA, Lewis F, Hall N, et al. Microsatellite instability in follicle centre cell lymphoma. Br J Haematol 1996;93:160-2.

11. de Wind N, Dekker M, van Rossum A, van der Valk M, te Riele H. Mouse models for hereditary nonpolyposis colorectal cancer. Cancer Res 1998;58:248-55.

12. Edelmann W, Yang K, Kuraguchi M, Heyer J, Lia M, Kneitz B, et al. Tumorigenesis in Mlh1 and Mlh1/Apc1638N mutant mice. Cancer Res 1999;59:1301-7.

13. Prolla TA, Baker SM, Harris AC, Tsao JL, Yao X, Bronner CE, et al. Tumour susceptibility and spontaneous mutation in mice deficient in Mlh1, Pms1 and Pms2 DNA mismatch repair. Nat Genet 1998;18:276-9.

14. Reitmair AH, Schmits R, Ewel A, Bapat B, Redston M, Mitri A, et al. MSH2 deficient mice are viable and susceptible to lymphoid tumours. Nat Genet 1995;11:64-70.

15. Edelmann W, Yang K, Umar A, Heyer J, Lau K, Fan K, et al. Mutation in the mismatch repair gene Msh6 causes cancer susceptibility. Cell 1997;91:467-77.

16. Ricciardone MD, Ozcelik T, Cevher B, Ozdag H, Tuncer M, Gurgey A, et al. Human MLH1 deficiency predisposes to hematological malignancy and neurofibromatosis type 1 . Cancer Res 1999;59:290-3.

17. Wang Q, Lasset C, Desseigne F, Frappaz D, Bergeron C, Navarro C, et al. Neurofibromatosis and early onset of cancers in hMLH1-deficient children. Cancer Res 1999;59:294-7.

18. Van der Valk MA. Survival, tumor incidence and gross pathology in 33 mouse strains. In: Hilgers J, Sluyser M, editors. Mammary tumors in the mouse. Amsterdam: Elsevier NorthHolland Biomedical Press; 1981. p. 46-115.

19. Bicknell DC, Kaklamanis L, Hampson R, Bodmer WF, Karran P. Selection for beta 2-microglobulin mutation in mismatch repairdefective colorectal carcinomas. Curr Biol 1996;6:1695-7. 